\title{
Effects of radiation on children
}

SIR - Dubrova et $a l .{ }^{1}$ reported that mutation rates at minisatellite loci in 79 children of parents who lived in heavily polluted areas of Belarus after the Chernobyl accident were twice that of 105 control children from the United Kingdom. They suggested that initial acute exposure to iodine-131 or chronic exposure of the parents to caesium-137 was responsible for the increased mutation rates, although they noted that the individual dose of ${ }^{137} \mathrm{Cs}$ "was estimated to be less than $5 \mathrm{mSv}$ per year, a value far

exposed parent, therefore fewer than 12 mutations were derived from exposed gametes. Although the total number of bands determined for the exposed gametes in our study is estimated to be 900 , approximately half of that in Belarus, we detected no increase of mutation rates at very similar minisatellite loci.

Dubrova et al. ${ }^{1}$ did not match parental ages as well as genetic and environmental factors affecting background mutation rates of the two populations. Before it is possible to conclude that the observed

MUTATIONS IN DNA FINGERPRINTS OF THE CHILDREN OF ATOMIC BOMB SURVIVORS

$\begin{array}{lccccc}\text { Group } & \begin{array}{c}\text { No. of } \\ \text { children }\end{array} & \begin{array}{c}\text { Total no. of } \\ \text { bands* in children }\end{array} & \begin{array}{c}\text { Bands } \\ \text { per child }\end{array} & \begin{array}{c}\text { No. of } \\ \text { mutations }\end{array} & \begin{array}{c}\text { Mutation } \\ \text { rate per band }\end{array} \\ \text { Exposed } & 64 & 1,111 & 17.36 & 12 & 0.011 \\ \text { Control } & 60 & 1,041 & 17.35 & 13 & 0.012\end{array}$

A probe (15.1.11.4), which includes the core region from DNA fingerprint probe 33.15, was used to detect the fingerprints.

*DNA fragments larger than $2.3 \mathrm{~kb}$ were counted.

below that predicted from mouse and human data." But they do not exclude the possibility of other contaminants such as industrial and agricultural pollutants, to which we add virus infections such as JC polyoma virus, which is suggested ${ }^{2}$ by the existence of rogue cells with extreme chromosome damage observed in Belarus ${ }^{3,4}$.

We recently reported a study ${ }^{5}$ of children of survivors of the Hiroshima/ Nagasaki atom bombs, in which we reported no genetic effects at six minisatellite loci after examining 50 exposed families with 64 children and 50 control families with 60 children. Except for parental exposure to radiation, the genetic and environmental backgrounds are identical and mean parental ages at the birth of the children are indistinguishable in the two groups. The mean mutation rate per locus per gamete at the six loci was $1.5 \%$ in the exposed, whose estimated mean dose was $1.9 \mathrm{~Sv}$, and $2.0 \%$ in the unexposed gametes. These values are similar to spontaneous germ-cell mutation rates detected in the Centre d'Etude du Polymorphisme Humain panel of 40 families $^{6}$ and the Dubrova et al. ${ }^{1}$ control group.

In preliminary examination of families in our study of the identical DNA fingerprints examined by Dubrova et al. ${ }^{1}$, we again could not detect any effects of radiation (see table). Contrary to the bands detected with single-locus probes, fingerprint bands of children were sometimes difficult to trace back to one parent, and we scored 12 and 13 mutations, respectively, for the exposed and the control families. Except for one child, each child of an exposed family had only one increase of the mutation rate in Belarus was caused by parental radiation exposure, it will be necessary to select new control Belarus families in which children born before the accident and parental ages at the birth of the children are matched to the parents having children after the accident, or at least looking at children born before the accident in the Belarus families already examined.

\section{Chiyoko Satoh}

\section{Mieko Kodaira}

Department of Genetics

Radiation Effects Research Foundation

5-2 Hijiyama Park,

Minami-ku,

Hiroshima 732, Japan

e-mail:csatoh@rerf.or.jp

DUBROVA $E T A L$. REPLY - We appreciate Satoh and Kodaira's point that the most appropriate control for our study would have been older children born to the same families before the Chernobyl accident. We discussed in our paper the difficulty of obtaining these controls, which forced us to use families from the United Kingdom as a control ${ }^{1}$. We would also like to comment on additional points raised by Satoh and Kodaira.

Satoh and Kodaira suggested that we should have matched the parental age at birth, given that mutation rate is known to increase with parental age for at least some classes of mutation ${ }^{7}$. The maternal age for the control and exposed groups in our study was $24.41 \pm 0.66$, s.d. $=5.35$ and $24.53 \pm 0.50$, s.d. $=5.58$, respectively $(t=0.14, P>0.05$; Bartlett test for homogeneity of group variances, $\chi^{2}=0.14$, d.f. $=1, P>0.05)$; the paternal age was $26.84 \pm 0.88$, s.d. $=7.18$ and $27.72 \pm 0.55$, s.d. $=6.05$, respectively $(t=0.90, P>0.05$; $\chi^{2}=2.58$, d.f. $\left.=1, P>0.05\right)$. The increase in mutation rate in the exposed group cannot therefore be explained by greater parental age.

We also discussed in our paper the possibility of mutation induction by other environmental pollutants. We stress that we found similar increases in mutation rate for three independent minisatellite systems. We have now extended these studies using additional loci, and again see an elevated mutation rate in the offspring of the same irradiated parents (unpublished data). We therefore believe that the difference in mutation rate found between the control and exposed families is most probably caused by environmental factors, including post-Chernobyl radioactive contamination. We also note that Satoh and Kodaira do not mention our dose-response analysis within the Belarus sample (Fig. 4 in our paper), which is consistent with the hypothesis of radiation induction of minisatellite mutation, and for which the control sample is irrelevant.

Satoh and Kodaira's own study on 5 minisatellites does not provide evidence for radiation-induced increase in mutation rate in the offspring of atomic bomb survivors in Hiroshima and Nagasaki. They also provide additional multilocus DNA fingerprint data which again point to no mutation increase. This apparent discrepancy could reflect the totally different nature of exposure in Japan following the atomic bomb explosions to that in the Chernobyl accident.

In summary, we note that our data, as well as those of Satoh and Kodaira ${ }^{5}$, are derived from relatively small numbers of families and that additional population surveys are needed to investigate the mechanisms and magnitude of minisatellite mutation induction seen in our study.

Yuri E. Dubrova*

Rita Newmann

David L. Neil

Alec J. Jeffreys

Department of Genetics,

University of Leicester,

Leicester LE1 7RH, UK

Valeri N. Nesterov

Nicolay G. Krouchinsky

Vladislav A. Ostapenko

Research Institute for Radiation Medicine,

Mogilev Branch,

Mogilev 212004, Belarus

1. Dubrova, Y. E. et al. Nature 380, 683-686 (1996)

2. Neel, J. V. et al. Proc. Natl Acad. Sci. USA 93 2690-2695 (1996).

3. Sevan'kaev, A. V. et al. Int. J. Radiat. Biol. 63, 361-367 (1993).

4. Scheid, W. et al. Health Phys. 64, 531-534 (1993).

5. Kodaira, M. et al Am J. Hum Genet 57, 1275-1283 (1995).

6. Jeffreys, A. J. et al. Nature 332, 278-281 (1988).

7. Vogel, F. \& Rathenberg, R. Adv. Hum. Genet. 5, 223-318 (1975)

*Also at: N. I. Vavilov Institute of General Genetics, Russian Academy of Sciences, Moscow B-333, Russia. To whom correspondence should be addressed; e-mail: yed2@le.ac.uk 